\title{
Human Recombinant Erythropoietin Promotes Differentiation of Murine Megakaryocytes In Vitro
}

\author{
Toshiyuki Ishibashi, James A. Koziol, and Samuel A. Burstein \\ Department of Basic and Clinical Research, Scripps Clinic and Research Foundation, La Jolla, California 92037
}

\begin{abstract}
To determine if erythropoietin affects megakaryocytopoiesis, we measured acetylcholinesterase (AchE) activity, a marker of the murine megakaryocytic lineage, after the addition of human recombinant erythropoietin to serumless murine bone marrow cultures. Erythropoietin increased AchE activity substantially. Moreover, when the hormone was added to serumless cultures of $\mathbf{4 2 6}$ isolated single megakaryocytes derived from megakaryocytic colonies, erythropoietin induced a significant increase in the diameters of these cells. From a Bayesian analysis of the likelihood that some megakaryocytes increased in DNA content during the culture period, we estimate that $61 \%$ of the cells increased in ploidy. These data indicate that the action of erythropoietin is not restricted to the erythroid lineage.
\end{abstract}

\section{Introduction}

Erythropoietin, known to be the primary humoral regulator of erythropoiesis, has been shown in some studies to promote megakaryocytopoiesis and increase the platelet count (1-8). These results have been controversial, however, because other laboratories have reported no influence of the hormone on the megakaryocytic lineage (9-11). The difficulties in evaluating the effect of erythropoietin on megakaryocytopoiesis include the impurities of the available preparations of the hormone, nonphysiologic concentrations employed, and the possibility that any potential effects of erythropoietin are mediated by accessory cells contaminating the progenitor cells in marrow cultures. In this report, we show that human recombinant erythropoietin $(\mathrm{rEpo})^{1}$ directly influences some aspects of murine megakaryocytic differentiation in culture.

This work was presented in part at the 27th Meeting of the American Society of Hematology, New Orleans, LA, 7-10 December 1985. This is Publication No. 4291 BCR from the Research Institute of Scripps Clinic.

Address reprint requests to Dr. Burstein, Department of Basic and Clinical Research (BCR5), Scripps Clinic and Research Foundation, 10666 North Torrey Pines Road, La Jolla, California 92037.

Received for publication 27 June 1986

1. Abbreviations used in this paper: AchE, acetylcholinesterase; $\beta$-ME, $\beta$-mercaptoethanol; IMDM, Iscove's modified Dulbecco's medium; rEpo, human recombinant erythropoietin.

J. Clin. Invest.

(c) The American Society for Clinical Investigation, Inc. $0021-9738 / 87 / 01 / 0286 / 04 \$ 1.00$

Volume 79, January 1987, 286-289

\section{Methods}

Mice. 6- to 8-wk-old specific pathogen-free C57Bl/6 males obtained from Jackson Laboratories (Bar Harbor, ME) were used for all experiments.

Liquid marrow cultures. Femoral marrow was flushed from the bones and made monodisperse by expulsion through an 18-gauge needle and then a 22-gauge needle. Marrow cells were treated with $0.5 \mathrm{mM}$ diisopropylfluorophosphate in $100 \%$ ethanol for $20 \mathrm{~min}$ to inactive endogenous cholinesterase prior to culture (12). $1 \times 10^{5}$ cells per well were cultured in a final volume of $0.2 \mathrm{ml}$ of Iscove's modified Dulbecco's medium (IMDM, Irvine Scientific, Santa Ana, CA) containing $1 \% \mathrm{Nu}$ tricyte (a serum-free medium supplement with albumin, transferrin, insulin, and lipids; J. Brooks Lab, San Diego, CA) and rEpo (Amgen Biologicals, Thousand Oaks, CA) over a four-log range of concentrations.

Quantitation of acetylcholinesterase (AchE) activity. AchE, a relatively specific marker of the megakaryocytic lineage in some rodents, was measured fluorometrically $(12,13)$. After $3 \mathrm{~d}$ in culture, each plate was centrifuged at $2,000 \mathrm{rpm}$ for $10 \mathrm{~min}$ and the supernatants of the wells were discarded. $0.2 \mathrm{ml}$ of a solution of $0.2 \%$ Triton X-100 in $1 \mathrm{mM}$ EDTA, $0.12 \mathrm{M} \mathrm{NaCl}$, and $50 \mathrm{mM}$ Hepes, $\mathrm{pH} 7.5$, was added to each well, followed by the addition of $20 \mu \mathrm{l}$ acetylthiocholine iodide (final concentration $0.56 \mathrm{mM}$ ). After $4 \mathrm{~h}$ of incubation, $10 \mu \mathrm{l}$ of $0.4 \mathrm{mM}$ coumarinphenylmaleimide (Molecular Probes Inc., Junction City, OR) in acetonitrile was added to $10 \mu \mathrm{l}$ of the reaction mixture in borosilicate glass tubes, followed by $2 \mathrm{ml}$ of $5 \mathrm{mM}$ sodium acetate, pH 5.0 , containing $1 \mathrm{mM}$ EDTA and $0.2 \%$ Triton X-100. The fluorescence emission was measured with a filter fluorometer with an excitation filter of $390 \mathrm{~nm}$ and an emission filter of $450 \mathrm{~nm}$.

Single cell cultures. Bone marrow was enriched for progenitor cells on a $1.070 / 1.077 \mathrm{~g} / \mathrm{cm}^{3}$ discontinuous Percoll gradient (13). $1-2 \times 10^{4}$ cells were cultured in IMDM containing $1 \%$ methylcellulose, $15 \%$ horse serum, $5 \%$ pokeweed mitogen-stimulated spleen cell conditioned medium (14), $50 \mu \mathrm{M} \beta$-mercaptoethanol ( $\beta$-ME), and $100 \mathrm{U} / \mathrm{ml}$ of penicillinstreptomycin in a humidified atmosphere of $5 \% \mathrm{CO}_{2}$ in air at $37^{\circ} \mathrm{C}$. After $5 \mathrm{~d}$ in culture, megakaryocytic colonies were identified in situ (15) and selectively removed under an inverted microscope with a micropipette in $2-\mu \mathrm{l}$ volumes and dispersed into $2 \mathrm{ml}$ of IMDM containing 50 $\mu \mathrm{M} \beta$-ME. Fewer than five colonies were plucked at a time to maximize the dilution of the initial culture constituents. Individual cells were removed in $1-\mu l$ volumes and recultured for $48 \mathrm{~h}$ in microtiter plate covers in $35 \mu \mathrm{l}$ of medium containing $3 \%$ crystalline bovine serum albumin, $50 \mu \mathrm{M} \beta-\mathrm{ME}, 1 \%$ Nutricyte, and $0.01 \mathrm{U} / \mathrm{ml}, 0.2 \mathrm{U} / \mathrm{ml}$, or $1 \mathrm{U} / \mathrm{ml}$ of rEpo. The final dilution of the initial culture constituents was at least 1 : 7,200 . Cell diameter was measured by determining the geometric mean of two perpendicular cell diameters using an inverted microscope equipped with an ocular micrometer before and after cell culture.

Ploidy analysis of single cells. After measurement of their diameters, single cells were placed on glass slides, fixed with $70 \%$ ethanol for 10 min and stained with $1.7 \times 10^{-5} \mathrm{M}$ chromomycin A3 (CalbiochemBehring Corp., La Jolla, CA). DNA content was measured by fluorescence cytophotometry as previously described (16). Granulocytes were used as diploid standards. A Bayesian classification rule was utilized to classify 49 cells into initial preculture ploidy classes, given their postculture ploidies and preculture diameters, as well as estimated frequency distributions 


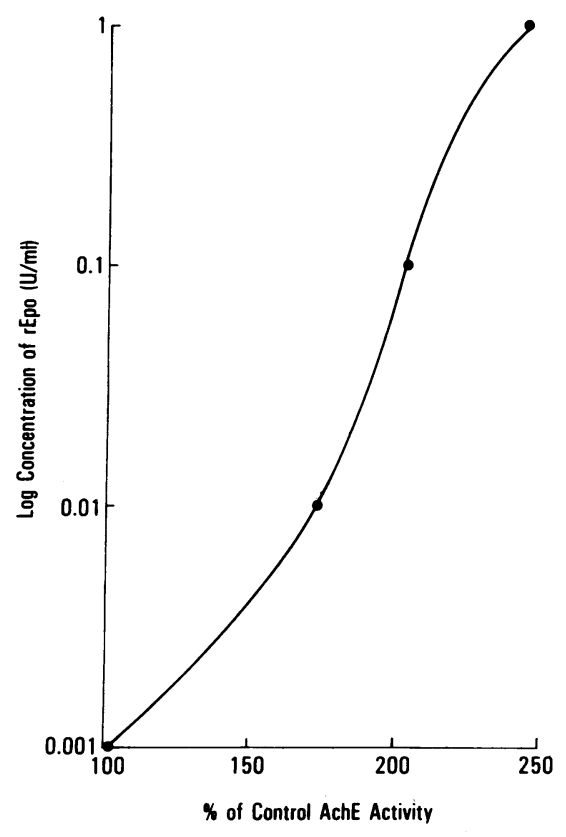

Figure 1. The promotion of AchE production in murine marrow cultures stimulated by human rEpo. At concentrations of $0.01 \mathrm{U} / \mathrm{ml}$, a significant increment in AchE production was observed $(P<.05)$ with further increases at higher concentrations.

of preculture diameters within each ploidy class (17). This analysis entails the calculation via Bayes' theorem of the posterior probabilities of membership in initial preculture ploidy classes for each of the 49 cells, and hence the posterior likelihood of ploidy shift.

\section{Results}

AchE activity was measured in serumless liquid cultures of murine marrow $3 \mathrm{~d}$ after the addition of rEpo. Fig. 1 shows a significant increase in AchE at a concentration of $0.01 \mathrm{U} / \mathrm{ml}$, with further increments noted at higher concentrations. Visual inspection of the cultures showed an increase both in the size and number of megakaryocytes when compared to control cultures without rEpo.

Table I. Effect of rEpo on the Size of Single Megakaryocytes

Number of cells increasing in diameter (\%)

\begin{tabular}{|c|c|c|c|c|}
\hline $\begin{array}{l}\text { Initial cell } \\
\text { diameter }\end{array}$ & $0 \mathrm{U} / \mathrm{ml}$ & $0.01 \mathrm{U} / \mathrm{ml}$ & $0.2 \mathrm{U} / \mathrm{ml}$ & $1 \mathrm{U} / \mathrm{ml}$ \\
\hline \multicolumn{5}{|l|}{$\mu m$} \\
\hline $12-20$ & $4 / 34(12)$ & $10 / 31(32)$ & $25 / 41(61)$ & $10 / 17(59)$ \\
\hline $20-25$ & $3 / 30(10)$ & $8 / 28(29)$ & $29 / 46(63)$ & $5 / 12(42)$ \\
\hline $25-30$ & $1 / 19(5)$ & $1 / 16(6)$ & $9 / 42(21)$ & $5 / 17(29)$ \\
\hline$>30$ & $0 / 14(0)$ & $1 / 20(5)$ & $3 / 36(8)$ & $2 / 23(9)$ \\
\hline
\end{tabular}

Cell diameter was measured on the same cells before and after culture with rEpo. An increase in diameter was defined as an increment of $\geq 0.5 \mu \mathrm{m}$. The range of increments was $0.5-10 \mu \mathrm{m}$.
Table II. Classification of 49 Cells into Preculture Ploidy Classes

\begin{tabular}{llrrr}
\hline & \multicolumn{5}{c}{ Observed postculture ploidy class $(n)$} \\
\cline { 2 - 5 } $\begin{array}{l}\text { Predicted preculture } \\
\text { ploidy class }(n)\end{array}$ & 4 & 8 & 16 & 32 \\
\hline 2 & 0 & 1 & 0 & 0 \\
4 & 1 & 4 & 1 & 0 \\
8 & & 10 & 15 & 3 \\
16 & & & 6 & 6 \\
32 & 1 & 15 & 22 & 11 \\
Total cells & & & & \\
\hline
\end{tabular}

The increase in AchE activity in the cultures may have been related to an increase in megakaryocytic proliferation and/or differentiation; moreover, the role of rEpo in this augmentation of AchE activity may have been mediated via accessory marrow cells. To determine if erythropoietin acted directly on megakaryocytes, $\mathrm{rEpo}$ at concentrations of $0.01-1 \mathrm{U} / \mathrm{ml}$ was added to single megakaryocytes isolated from megakaryocytic colonies. Cell diameter was measured on 426 megakaryocytes at the outset of culture and $48 \mathrm{~h}$ later. As shown in Table I, rEpo promoted an increment in diameter, the response being dependent both on the concentration of the hormone and the initial cell diameter. Isolated granulocytes $(n=30)$ cultured in the same manner did not change in diameter.

A Bayesian rule was used to classify cells into ploidy classes at the outset of culture, given their preculture cell diameters and postculture ploidies (17). A summary of the classification results is given in Table II. On the basis of observed postculture ploidy class and our estimated prior densities of cell diameters, we would estimate a substantial number of cells ( 30 of 49 or $61 \%$ ) to have shifted ploidy class while growing in culture. Indeed, as shown in Table III, a monotone trend in probability of shift may be discerned; we would predict $0 \%, 33 \%, 73 \%$, and $82 \%$ of cells in ploidy classes $4,8,16$, and $32 n$, respectively, to have shifted ploidy class while growing in culture. Fig. 2 illustrates the appearance of a typical megakaryocyte after $48 \mathrm{~h}$ in culture with $0.2 \mathrm{U} / \mathrm{ml}$ of $\mathrm{rEpo}$.

\section{Discussion}

Although studies in experimental animals and some clinical data suggest that erythropoietin may influence megakaryocytopoiesis,

Table III. Estimated Numbers of Shifts in Ploidy Class among 49 Cells during Culture

\begin{tabular}{llrrr}
\hline & \multicolumn{5}{l}{ Observed postculture ploidy class $(n)$} \\
\cline { 2 - 5 } & 4 & 8 & 16 & 32 \\
\hline & 0 & 5 & 16 & 9 \\
Predicted shifts & 1 & 10 & 6 & 2 \\
Predicted nonshifts & 0 & 33 & 73 & 82 \\
Percentage shifts & & & & \\
\hline
\end{tabular}




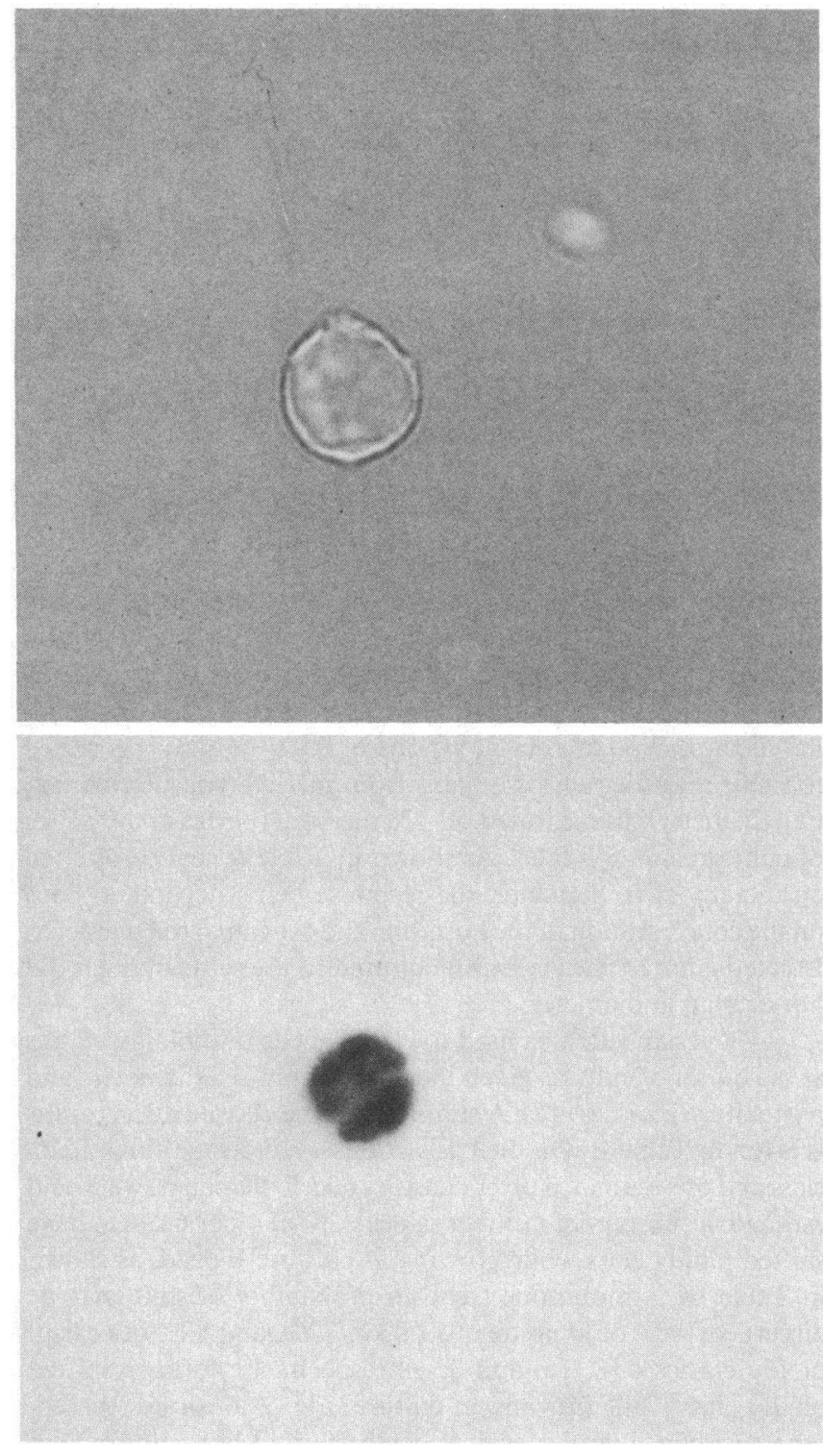

Figure 2. $(A)$ A single megakaryocyte after culture in the presence of $0.2 \mathrm{U} / \mathrm{ml} \mathrm{rEpo}$. Initial diameter was $20.8 \mu \mathrm{m}$. The final diameter before fixation was $26.1 \mu \mathrm{m}(\times 500)$. (B) The identical cell observed under fluorescein optics. The measured ploidy was $32 \mathrm{~N}(\times 500)$.

the multitude of effects of the experimental manipulations and the complexity of the clinical situations have precluded a definitive conclusion (4, 5, 18-21). More recent studies employing in vitro marrow culture have not resolved the question (1-3, 911). However, the data of Williams et al. (6), Dukes et al. (7), and Mizoguchi et al. (8) suggest that purified or recombinant erythropoietin may stimulate megakaryocytic colony formation in cultures of whole marrow. The production of rEpo in purified form has allowed for a more precise reexamination of the role of erythropoietin in megakaryocytopoiesis. In serumless liquid marrow cultures, the hormone promoted AchE production, a marker of megakaryocytes in mice and some other species (12). To determine if rEpo promoted some aspects of megakaryocytic differentiation, we measured the size of individual megakaryo- cytes derived from colonies before and after culture with rEpo. In the megakaryocytic lineage size is one generally accepted marker of differentiation (22). At concentrations of erythropoietin achievable in vivo $(\sim 0.01 \mathrm{U} / \mathrm{ml})$, a significant increment in size was observed. Polyploidy is another well-known characteristic of differentiated megakaryocytes. Although we were unable to preselect single megakaryocytes of a particular ploidy class prior to culture with rEpo, we would infer from a Bayesian analysis of our data that some megakaryocytes have increased in ploidy.

The studies reported herein demonstrate that rEpo is sufficient to promote some aspects of murine megakaryocytic differentiation in vitro, indicating that the influence of erythropoietin is not restricted to the erythroid lineage. The role of erythropoietin in the regulation of thrombocytopoiesis in vivo remains to be ascertained.

\section{Acknowledgments}

We thank the BCR Word Processing Center for preparation of the manuscript.

This study was supported by grant HL 29037 from the National Institutes of Health.

\section{References}

1. McLeod, D. L., M. M. Shreeve, and A. A. Axelrad. 1976. Induction of megakaryocyte colonies with platelet formation in vitro. Nature (Lond.). 261:492-494.

2. Vainchenker, W., J. Bouguet, J. Guichard, and J. Breton-Gorius. 1979. Megakaryocyte colony formation from human bone marrow precursors. Blood. 54:940-945.

3. Freedman, M. H., T. P. McDonald, and E. F. Saunders. 1981. Differentiation of murine marrow megakaryocyte progenitors (CFUm): humoral control in vitro. Cell Tissue Kinet. 14:53-58.

4. Choi, S. I., and J. V. Simone. 1973. Platelet production in experimental iron deficiency anemia. Blood. 42:219-228.

5. Jackson, C. W., J. V. Simone, and C. C. Edwards. 1974. The relationship of anemia and thrombocytosis. J. Lab. Clin. Med. 84:357368.

6. Williams, N., H. Jackson, N. N. Iscove, and P. P. Dukes. 1984. The role of erythropoietin, thrombopoietic stimulating factor, and myeloid colony-stimulating factors on murine megakaryocyte colony formation. Exp. Hematol. 12:734-740.

7. Dukes, P. P., J. C. Egrie, T. W. Strickland, J. K. Browne, and F.-K. Lin. 1986. Megakaryocyte colony stimulating activity of recombinant human and monkey erythropoietin. In Megakaryocyte Development and Function. R. F. Levine, N. Williams, J. Levin, and B. L. Evatt, editors. Alan R. Liss, Inc., New York. 105-109.

8. Mizoguchi, H., Y. Fujiwara, R. Sasaki, and H. Chiba. 1986. The effect of interleukin-3 and erythropoietin on murine megakaryocyte colony formation. In Megakaryocyte Development and Function. R. F. Levine, N. Williams, J. Levin, and B. L. Evatt, editors. Alan R. Liss, Inc., New York. 111-115.

9. Evatt, B. L., J. L. Spivak, and J. Levin. 1976. Relationships between thrombopoiesis and erythropoiesis: with studies of the effects of preparations of thrombopoietin and erythropoietin. Blood. 48:547-558.

10. Mazur, E. M., R. Hoffman, and E. Bruno. 1981. Regulation of human megakaryocytopoiesis: An in vitro analysis. J. Clin. Invest. 68: 733-741.

11. Levin, J., F. C. Levin, D. F. Hull III, and D. G. Penington. 1982. The effects of thrombopoietin on megakaryocyte-CFU, megakaryocytes, 
and thrombopoiesis: with studies of ploidy and platelet size. Blood. 60: 989-998.

12. Burstein, S. A., C. N. Boyd, and G. L. Dale. 1985. Quantitation of megakaryocytopoiesis in liquid culture by enzymatic determination of acetylcholinesterase. J. Cell. Physiol. 122:159-165.

13. Ishibashi, T., and S. A. Burstein. 1985. Separation of murine megakaryocytes and their progenitors on continuous gradients of Percoll. J. Cell. Physiol. 125:559-566.

14. Ishibashi, T., and S. A. Burstein. 1986. Interleukin 3 promotes the differentiation of isolated single megakaryocytes. Blood. 67:15121514.

15. Burstein, S. A., J. W. Adamson, D. Thorning, and L. A. Harker. 1979. Characteristics of murine megakaryocytic colonies in vitro. Blood. 54:169-179.

16. Chatelain, C., and S. A. Burstein. 1984. Fluorescence cytopho- tometric analysis of megakaryocytic ploidy in culture: Studies of normal and thrombocytopenic mice. Blood. 64:1193-1199.

17. Anderson, T. W. 1958. An Introduction to Multivariate Statistical Analysis. John Wiley \& Sons. New York. 142-147.

18. De Gabriele, G., and D. G. Penington. 1967. Physiology of the regulation of platelet production. Br. J. Haematol. 13:202-209.

19. Langdon, J. R., and T. P. McDonald. 1977. Effects of chronic hypoxia on platelet production in mice. Exp. Hematol. 5:191-198.

20. Schloesser, L. L., M. A. Kipp, and F. J. Wenzel. 1965. Thrombocytosis in iron-deficiency anemia. J. Lab. Clin. Med. 66:107-114.

21. Hirsh, J., and J. V. Dacie. 1966. Persistent post-splenectomy thrombocytosis and thrombo-embolism: A consequence of continuing anaemia. Br. J. Haematol. 12:44-53.

22. Levine, R. F., K. C. Hazzard, and J. D. Lamberg. 1982. The significance of megakaryocyte size. Blood. 60:1122-1131. 